tion of infusion) are considered, the results of the experiments of Grossman et al. (1961) may not be at variance with those of the present study. Thus we suggest on the basis of the present studies that gastrointestinal blood loss associated with the usual doses of unbuffered acetylsalicylic acid can be fully explained by a local action on gastric mucosa, and that a systemic mechanism need not be postulated.

We are grateful to Miss Joan Moulang for technical assistance, to the subjects for their co-operation, and to Mr. David Paix, physicist, Prince Henry Hospital, for advice and for the use of the Armac counter. This work was supported in part by the Bushell Trust.

\section{REFERENCES}

Anderson, K. W. (1964). Archives Internationales de Pharmacodynamie et Thérapie, 152, 379.

Barbour, H. G., and Dickerson, V. C. (1938). Archives Internationales de Pharmacodynamie et Thérapie, 58, 78.
Beeken, W. L. (1968). Gut, 9, 475.

Brodie, D. A., and Chase, B. J. (1967). Gastroenterology, 53, 604.

Caravati, C. M., and Cosgrove, E. F. (1946). Annals of Internal Medicine, 24, 638.

Clark, B. B., and Adams, W. L. (1947). Gastroenterology, 9, 461.

Davison, C., Hertig, D. H., and DeVine, R. (1966). Clinical Pharmacology and Therapeutics, 7, 239.

Goulston, K., and Cooke, A. R. (1968). British Medical fournal, 4, 664. Goulston, K., and Skyring, A. (1964). Gut, 5, 463.

Grossman, M. I., Matsumoto, K. K., and Lichter, R. J. (1961). Gastroenterology, 40, 383.

Hurley, J. W., and Crandall, L. A. (1964). Gastroenterology, 46, 36.

Lynch, A., Shaw, H., and Milton, G. W. (1964). Gut, 5, 230.

Schanker, L. S., Shore, P. A., Brodie, B. B., and Hogben, C. A. M. (1957). Fournal of Pharmacology and Experimental Therapeutics, $120,528$.

Smith, M. J. H.; and Smith, P. K. (1966). The Salicylates. New York, Interscience.

Snedecor, G. W., and Cochran, W. G. (1967). Statistical Methods, 6th ed. Ames, Iowa, Iowa State University Press.

Trinder, P. (1954). Biochemical fournal, 57, 301.

Weiss, H. J., Aledort, L. M., and Kochwa, S. (1968). Fournal of Clinical Investigation, 47, 2169.

\title{
Chest $X$-ray Film in Acute Myocardial Infarction
}

\author{
A. E. TATTERSFIELD, ${ }^{*}$ M.B., M.R.C.P.; M. W. MCNICOL, $\dagger$ M.B., F.R.C.P.GLASG. \\ H. SHAWDON, $\ddagger$ M.R.C.P., D.M.R.D., F.F.R. ; D. ROLFE, $§$ M.B., M.R.C.P.
}

British Medical fournal, 1969, 3, 332-335

\begin{abstract}
Cummary : A total of 185 chest x-ray films taken on 50 consecutive admissions to a coronary care unit were assessed independently for specific abnormalities by three observers. The commonest abnormality was upper lobe pulmonary venous congestion. When this was present by itself it did not appear to affect prognosis. Pulmonary oedema occurred in 12 of the patients, was associated with more pronounced pulmonary venous congestion (but not necessarily with cardiac enlargement), and usually cleared within five days. Generalized cardiac enlargement and septal lines were rarely seen. Clinically silent nonsegmental shadows were found in six patients.

No consistent change in radiological abnormality was found in the first three days after infarction, but thereafter a gradual improvement occurred, so that before discharge the $x$-ray picture was nearly normal. There was good correlation between the presence and extent of lung crepitations and the presence of pulmonary oedema on the chest x-ray film.
\end{abstract}

It is suggested that the chest $x$-ray film is a useful additional index of the severity of heart failure in myocardial infarction.

\section{Introduction}

The chest $x$-ray film is helpful in the diagnosis of left heart failure, but its value as a routine investigation in myocardial Infarction has not been established. Florid pulmonary oedema is uncommon, but the majority of patients have some signs of

- Registrar.

† Consultant Physician.

$\mp$ Radiologist.

House Physician.

Central Middlesex Hospital, London N.W.10. left heart failure (MacKenzie et al., 1964 ; McNicol et al., 1965 ; Fluck et al., 1967), and lesser radiological signs would be expected to be common. We have therefore reviewed the chest $x$-ray films routinely taken of the first 50 patients admitted to the coronary care unit at Central Middlesex Hospital in an attempt to evaluate the diagnostic use of portable chest $x$-ray films in myocardial infarction and to assess the frequency and significance of individual signs of left heart failure.

\section{Patients}

The subjects reviewed were the first 50 patients admitted to the coronary care unit with a definite myocardial infarction (typical history with characteristic electrocardiographic (E.C.G.) changes or fewer E.C.G. signs (W.H.O., 1959) and a diagnostic rise in serum enzymes: serum hydroxybutyrate dehydrogenase exceeding 150 i.u./litre). The patients were selected only to the extent that men under the age of 65 years and older men or women with complicated infarctions were preferentially admitted, and in that they survived long enough to have a chest $x$-ray film taken. There were 49 men and one woman. The age range was 38 to 68 (mean 54) years. None of the patients had cardiogenic shock.

The patients were assessed by detailed physical examination on admission, with particular reference to clinical evidence of cardiac failure. Note was also made of any history of chronic bronchitis or hypertension (diastolic blood pressure known at any time to have exceeded $110 \mathrm{~mm}$. $\mathrm{Hg}$ or settling above this level in convalescence).

Treatment depended on the overall assessment of the patient's condition and policy in the coronary care unit. Heart failure was treated vigorously; 39 patients received diuretics and 16 received digitalis. As treatment for heart failure was in part 
influenced by the chest $x$-ray picture no attempt to correlate treatment and the chest $x$-ray findings has been made. Five patients received morphine after admission, six required lignocaine or procainamide, and eight received sedation.

The patients usually remained in the unit for three days. During this time clinical examination was made twice daily.

\section{X-ray Examination}

Portable anteroposterior chest $x$-ray films at a tube-film distance of 6 feet $(180 \mathrm{~cm}$.) were taken on admission and each morning thereafter as long as the patient remained in the unit. So far as their clinical condition permitted the patients were seated upright in bed. After discharge from the unit, $x$-ray films were taken at the discretion of the physician in charge of the patient. Some of these were portable films, but during convalescence some films were taken in the $x$-ray department.

The $x$-ray films were assessed independently by three observers who were unaware of the clinical findings but who assessed all the films of each patient serially. They also assessed the quality of the films as good, adequate, or poor. Poor films were discarded.

The following abnormalities were specifically sought on each $x$-ray film: (1) cardiac enlargement; (2) congestion of the upper lobe pulmonary veins; (3) intra-alveolar pulmonary oedema-patchy ill-defined shadowing of more or less uniform density (Gleason and Steiner, 1966); (4) pleural effusions; (5) septal lines (Kerley, 1933); (6) widening of the superior mediastinal shadow.

Each film was given a total chest $x$-ray score (see Appendix), which gave an arbitrary assessment of left ventricular failure. The presence of other radiological abnormalities was also noted.

\section{Results}

Quality of X-ray Films.-One hundred and fifty-six portable films and $34 x$-ray department films were available for the 50 patients. Five of the portable films were judged to be of poor quality and were discarded, leaving a total of 185 films for analysis. The detail of assessment of film quality is shown in Table I.

\begin{tabular}{|c|c|c|c|c|}
\hline \multirow{2}{*}{ Place of $X$-ray Examination } & \multicolumn{3}{|c|}{ Quality of Film } & \multirow{2}{*}{$\begin{array}{c}\text { Total } \\
\text { for Analysis }\end{array}$} \\
\hline & Poor & Adequate & Good & \\
\hline $\begin{array}{ll}\text { Ward } & \cdots \\
\text { X-ray dept. } & .\end{array}$ & ${ }_{0}^{5}(3 \%)$ & $\begin{array}{r}69(44 \%) \\
6(18 \%)\end{array}$ & $\begin{array}{l}82(53 \%) \\
28(82 \%)\end{array}$ & $\begin{array}{r}151 \\
34\end{array}$ \\
\hline
\end{tabular}

Abnormalities.-Table II lists the incidence of the abnormal findings on the initial film and the total incidence of abnormalities. The initial $x$-ray films were divided into two groups: those in group 1 were normal or showed upper lobe pulmonary venous congestion only, whereas those in group 2 showed further abnormalities.

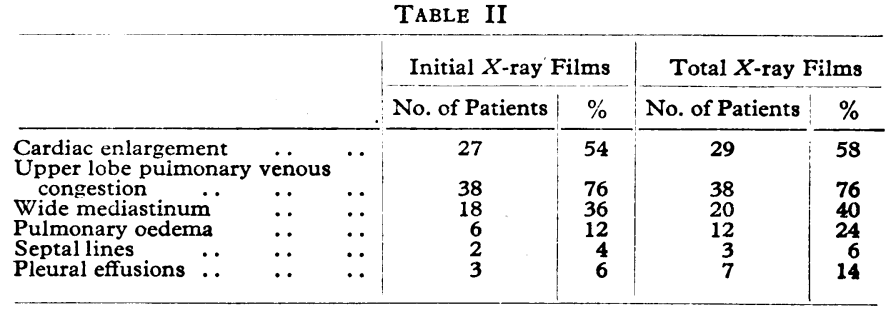

\section{Group 1}

Initial Film Essentially Normal or Showing Pulmonary Venous Congestion Only (17 Patients).-These 17 patients had either a completely normal film (nine patients) or mild upper lobe pulmonary venous congestion on the initial film. Subsequent films are available for 14 of these patients. In 13 no abnormalities developed. One patient had a pleural effusion after an episode of ventricular fibrillation. The clinical course in all of these patients was uneventful apart from the one episode of ventricular fibrillation in one patient. Basal lung crepitations were present in nine patients.

\section{Group 2}

Initial Film Abnormal (33 Patients).-Each abnormality is considered separately.

Cardiomegaly. - Twenty-seven of these patients had some cardiomegaly. The majority showed only a moderate increase in heart size, only three showing pronounced cardiomegaly. Six patients in this group had a normal-sized heart. Four of these six had pulmonary oedema and all had pulmonary venous congestion.

Pulmonary Venous Congestion.-This was present in 30 of these 33 patients. Twenty-four initially had moderate pulmonary venous congestion. In 18 this did not increase, but in six with initial moderate pulmonary venous congestion there was deterioration. A further six had marked initial pulmonary venous congestion. Thus 12 patients had marked pulmonary venous congestion at some stage ; nine of these also had pulmonary oedema. Three patients whose initial chest $x$-ray film showed several other abnormalities had had no pulmonary venous congestion at any time.

Pulmonary Oedema.-This was present on the initial film in six patients and developed in a further six (day 2 in four patients, day 4 in one patient, and day 15 in one patient with second infarction), making a total incidence of $24 \%$. Pulmonary venous congestion was invariably present in patients with pulmonary oedema. Moderate cardiac enlargement presented in 8 of the 12 patients, pleural effusions in 3, and septal lines in 2. Pulmonary oedema was present for 2 to 10 days (mean duration 5 days). Four of the patients died, though none of the deaths was directly the result of pulmonary oedema. Four patients with pulmonary oedema in whom the heart size was initially normal subsequently developed cardiac enlargement-one while oedema was still present and three after its resolution.

Pleural Effusion.-These were found in seven patients (14\%). The site of effusion and time of occurrence are shown in Table III.

\begin{tabular}{llll|l|c|c}
\multicolumn{8}{c|}{ TABLE III } \\
\hline \multicolumn{3}{c}{ Site of Effusion } & & & No. & Days After Infarction \\
\hline Right & $\cdots$ & $\cdots$ & $\cdots$ & $\cdots$ & 3 & $2,5,7$ \\
Left & $\cdots$ & $\cdots$ & $\cdots$ & $\cdots$ & 2 & 1,4 \\
Bilateral & $\cdots$ & $\cdots$ & $\cdots$ & $\cdots$ & 2 & 1,1 \\
\hline
\end{tabular}

Septal Lines.-Septal lines (Kerley, 1933) were found in only three patients. Two had septal lines on the initial $x$-ray filmone was hypertensive and had a history of previous infarction and the other was in florid pulmonary oedema. In both patients the septal lines had cleared by the fourth day. The third patient, who had marked cardiac enlargement on admission, developed septal lines on the fourth day. These had cleared by the tenth day.

Total Chest X-ray Score.-The maximum score possible was 36 (see Appendix). The range encountered in these patients was $0-24$, with a group mean value of 6.4. The mean chest $x$-ray scores of the small number of patients receiving morphine, antiarrhythmic drugs, and sedation were 4.0,6.1, and $9 \cdot 0$ respectively; none differed significantly from the group mean value of $6 \cdot 4$. 


\section{Correlation of X-ray with Clinical Findings}

Examination of the patients at the time of initial $x$-ray examination showed that $12(24 \%)$ had no lung crepitations, $34(68 \%)$ had basal crepitations only, and $4(8 \%)$ had widespread signs. Basal and widespread lung crepitations occurred more often in those patients with abnormal chest $\boldsymbol{x}$-ray pictures than in those with no or minimal abnormalities $(P<0.02)$, none of whom had widespread crepitations.

Table IV shows that the occurrence of lung crepitations appears to be uninfluenced by the presence or absence of pulmonary venous congestion on the initial $\boldsymbol{x}$-ray films. Pulmonary oedema, however, either on the initial or subsequent films showed a significant association with lung crepitations which tended to be more widespread $(P<0.05)$. Only one of the 12 patients with pulmonary oedema had no lung crepitations, nor in fact any other signs of heart failure. Conversely, one patient with widespread crepitations had no pulmonary oedema on the chest $x$-ray film at any time.

TABLE IV.-Distribution of Lung Crepitations in Patients with Pulmonary Venous Congestion and Pulmonary Oedema

\begin{tabular}{|c|c|c|c|c|}
\hline & $\begin{array}{c}\text { No. of } \\
\text { patients }\end{array}$ & $\begin{array}{l}\text { \% with } \\
\text { No } \\
\text { crepitations }\end{array}$ & $\begin{array}{c}\% \text { with } \\
\text { basal } \\
\text { crepitations }\end{array}$ & $\begin{array}{l}\% \text { with } \\
\text { widespread } \\
\text { crepitations }\end{array}$ \\
\hline 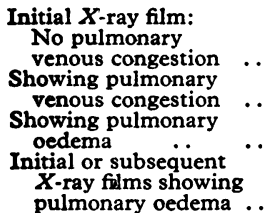 & $\begin{array}{r}12 \\
38 \\
6 \\
12\end{array}$ & $\begin{array}{r}25 \\
24 \\
0\end{array}$ & $\begin{array}{l}75 \\
65 \\
67\end{array}$ & $\begin{array}{r}0 \\
11 \\
33\end{array}$ \\
\hline
\end{tabular}

\section{Influence of Hypertension}

Six patients were hypertensive. Three of these had widespread crepitations and pulmonary oedema on the chest $x$-ray film. They formed a high proportion of the patients with widespread crepitations (three out of four) and of the patients showing pulmonary oedema on the initial film (three out of six). Although the total chest $x$-ray score was higher in these patients $(10 \cdot 1$ as against $6 \cdot 4)$ it did not reach conventional levels of significance $(P<0 \cdot 1)$.

\section{Influence of Chronic Bronchitis}

The clinical features and chest $x$-ray picture in the eight patients with chronic bronchitis did not differ from the group as a whole.

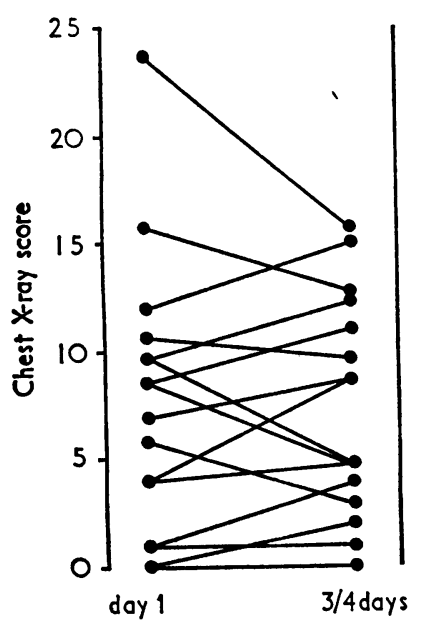

FIG. 1

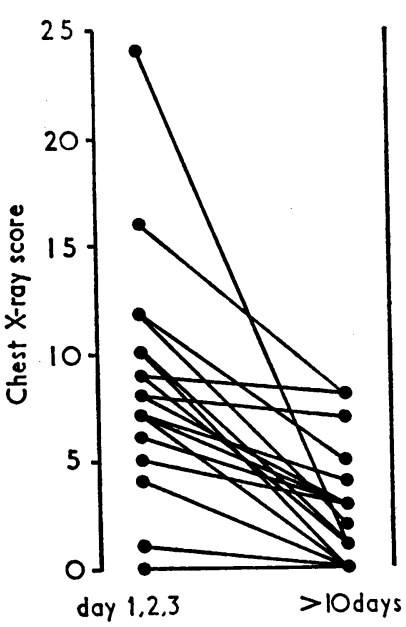

FIG. 2
Age

The results showed a wide scatter with a tendency for the score to increase with increasing age $(r=+0 \cdot 245)$.

\section{Progress of Chest X-ray Films}

Films of 16 patients taken within 24 hours of admission were compared with those taken 72 to 96 hours later. Although in individual patients there were pronounced changes, both improvement and deterioration (Fig. 1), there were no overall changes in the mean $x$-ray score (7.4 on day 1 and on day 3$)$.

In 18 patients the initial film was compared with a film taken at least 10 days after admission (Fig. 2). There was a highly significant fall in mean $x$-ray score (8.1 on day 1 to 2.5 at $10+$ days, $P<0.01)$. This improvement occurred gradually after the first three days (Fig. 3).

\section{Other Pulmonary Shadows}

Of the 50 patients six had non-segmental shadows on the $x$-ray film. Four of the six had a cardiac arrest and three died, a mortality of $50 \%$, compared with a mortality of $14 \%$ in the remaining 44 patients. These changes were clinically silent. In two patients seen at necropsy there was no evidence of pulmonary embolism or infarction.

\section{Discussion}

Little has been written about the chest $x$-ray picture in the acute stages of myocardial infarction. Portable films have to be taken and quantitative assessment of abnormality is very difficult. We felt, however, that a retrospective survey of our $x$-ray films would be of value.

The quality of the films was surprisingly good, particularly as several patients were too ill to be able to co-operate. The standard has continued to improve because daily films are now taken as a routine procedure. The quality permitted assessment of abnormality without difficulty.

The commonest abnormality was distension of the upper lobe pulmonary veins $(76 \%)$. When this was the only abnormality on the film it seemed to be of little significance. Cardiac enlargement tended to be associated with pulmonary venous congestion, but in a few patients cardiac enlargement appeared when pulmonary venous congestion and pulmonary oedema were clearing. The mechanism regarding this is uncertain,

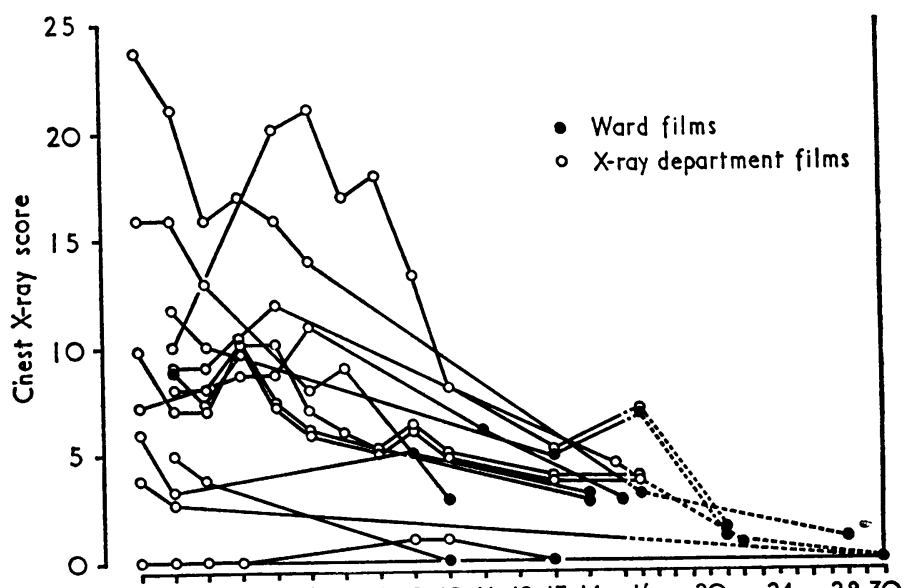

Days $1 \begin{array}{llllllllllllllllllllllllllll}2 & 3 & 4 & 5 & 6 & 7 & 8 & 9 & 10 & 11 & 12 & 13 & 14 & 16 & 20 & 24 & 28 & 30\end{array}$

FIG. 3

Fig. 1.-Changes in chest $x$-ray score from 24 hours to 72-96 hours aft er infarction (16 patients). Fig. 2.-Changes in chest $x$-ray scores from 24 hours to at least 10 days after infarction (18 patients). FIG. 3. - Changes in chest $x$-ray score with time in 14 patients. 
but it may be related to a change in pattern, of left ventricular pressure-volume relationships.

Distension of the pulmonary veins is related to increased pulmonary venous pressure, to increased pulmonary blood flow to the lung as a whole, or to increased upper lobe blood flow, possibly due to vasoconstriction elsewhere in the lung (cf. mitral stenosis-Doyle et al., 1956 ; Simon, 1958).

It is known that in myocardial infarction cardiac output is commonly reduced and pulmonary artery pressure raised (Fluck et al., 1967 ; Gilbert et al., 1954). There is conflicting evidence on left ventricular pressures in myocardial infarction (Kirby et al., 1968 ; Nixon, 1968), but undoubtedly left ventricular end-diastolic pressure is raised in some patients, who will as a result have pulmonary venous hypertension. This would account for our findings. An additional factor may be redistribution of blood flow as a result of lower lobe vasoconstriction due to increased interstitial pressure in the lower lobe (Hughes et al., 1967).

Pulmonary oedema was initially present or developed in a total of 12 patients $(24 \%)$. All of these had pulmonary venous congestion, severe in four, and there was an increase in heart size in eight. Four patients had pulmonary oedema with normal heart size.

The value of the other radiological signs is more doubtful. Septal lines were found in only three patients. It has been shown that in mitral valve disease septal lines are almost invariably present when the pulmonary capillary wedge pressure exceeds $20 \mathrm{~mm}$. $\mathrm{Hg}$ (Grainger, 1958). There may, however, be differences between the chronic pulmonary hypertension of mitral disease and the acuter changes of myocardial infarction. In the two cases reported by Kirby et al. (1968) left ventricular end-diastolic pressures were known to exceed $20 \mathrm{~mm}$. $\mathrm{Hg}$ (23 and $33 \mathrm{~mm}$.), but septal lines were not present on the chest $x$-ray film. This would support the suggestion made by Grainger (1958) that in acute left ventricular failure the alveoli are freely permeable, so that oedema is alveolar rather than interstitial and septal lines are less prominent. It is, however, not clear how the three patients with septal lines in this group differed from the remainder. In one there was a previous history of heart disease and possible cardiac failure, the second had pronounced cardiomegaly, but the third had no such distinguishing features.

Widening of the superior mediastinum showed an association with pulmonary venous congestion, cardiac enlargement, and the clinical findings of basal crepitations. This finding, however, is affected by so many factors, notably position of the patient and variation in depth of inspiration, that it is difficult to regard it as a significant sign.

It has been previously shown in this department that the presence of persistent lung crepitations is a reproducible clinical sign (Barnes et al., 1967) and that when there are crepitations prognosis is worse and arterial hypoxaemia and acidosis are more severe (McNicol et al., 1965). In the group of patients under review a correlation has been found between the clinical extent of lung crepitations, the presence of pulmonary oedema on the $x$-ray film, and the arbitrary total $x$-ray score. The existence and extent of lung crepitations in any individual patient, however, may not correlate well with radiological assessment of the severity of left ventricular failure. Lung crepitations are thought to be due to alveolar oedema, which, though clinically and radiologically apparent, may not be as important as interstitial oedema in the disturbance of lung function. In our experience the other signs of left heart failure, such as third heart sounds, gallop rhythm, or reversed splitting of the second heart sound, show such a degree of observer variation as to preclude their use in any systematic comparison.
The arbitrary total chest $x$-ray score proved of some value in following the patient's progress. In the first three days there were no consistent changes, but in all patients followed for more than 10 days there was a noticeable though slow improvement. By the time of discharge from hospital persisting abnormalities were few. This improvement parallels the haemodynamic improvement reported by Valentine et al. (1966).

In six patients transient pulmonary shadows of uncertain cause were found. These have usually been attributed to pulmonary embolism with infarction, but none of our patients had any clinical evidence to support this diagnosis. Three of these patients died, and at necropsy on two of them no cause for the radiological abnormality could be found; a special search revealed no pulmonary emboli. The cause of the transient shadows remains obscure. We believe the associated high mortality to be coincidental.

\section{Appendix}

Individual Items on Chest X-ray Film.-Individual items on the chest $x$-ray film (such as pulmonary oedema) were assessed by each observer for each film as: absent or normal, 0 ; moderately abnormal, 1 ; markedly abnormal, 2 . The total when summated for all three observers was therefore 0 to 6 . This was then classified as: 0 and $1=a ; 2,3$, and $4=b$; 5 and $6=c$. The $\chi^{2}$ test was used to assess significance between individual items.

Total Chest $X$-ray Score.-An arbitrary chest $x$-ray score was compiled for each film to give some assessment of left ventricular failure. This score consisted of the sum of the item scores for all six items-that is, giving a maximum score of 36 . Chest $x$-ray scores were compared by Wilcoxon's rank sum test.

We would like to thank all the radiographers for their co-operation. A. E. T. and $M . W . M c N$. are receiving grants from the Medical Research Council. The Ministry of Health is helping to support the coronary care unit.

Requests for reprints should be made to A. E. Tattersfield.

\section{REFERENCES}

Barnes, S. A., et al. (1967). Middlesex Hospital fournal, 67, 133.

Doyle, A. E., Goodwin, J. F., Harrison, C. V., and Steiner, R. E.. (1957). British Heart fournal, 19, 353.

Fluck, D. C., et al. (1967). British Heart fournal, 20, 748.

Gilbert, R. P., Goldberg, M., and Griffin, J. (1954). Circulation, 9, 847.

Gleason, D. C., and Steiner, R. E. (1966). American fournal of Roentgenology, 98, 279.

Grainger, R. G. (1958). British fournal of Radiology, 31, 201.

Hughes, J. M. B., Glazier, J. B, Maloney, J. E., and West, J. B. (1967). Lancet, 1, 192.

Kerley, P. (1933). British Medical fournal, 2, 594.

Kirby, B. J., McNicol, M. W., and Tattersfield, A. E. (1968). Lancet, $1,944$.

MacKenzie, G. J., Taylor, S. H., Flenley, D. C., McDonald, A. H., Staunton, H. P., and Donald, K. W. (1964). Lancet, 2, 825.

McNicol, M. W., Kirby, B. J., Bhoola, K. D., Everest, M. E., Price, H. V., and Freedman, S. F. (1965). British Medical fournal, 2, 1270 .

Nixon, P. G. F. (1968). Lancet, 2, 146.

Simon, M. (1958). Fournal of the Faculty of Radiologists, 9, 25.

Valentine, P. A., Fluck, D. C., Mounsey, J. P. D., Reid, D., Shillingford, J. P., and Steiner, R. E. (1966). Lancet, 2, 837.

World Health Organization (1959). World Health Organization Technical Report Series, No. 168. 